\title{
Chest Wall Paraesthesia After Thoracic Surgery
}

\author{
Luis Berlanga González, Orlando Gigirey Castro \\ and Sara de Cabanyes Candela \\ Thoracic Surgery Service, Hospital San Pedro de Alcántara, \\ Cáceres \\ Spain
}

\section{Introduction}

Post-operative pain after thoracic surgery is particularly intense and prolonged when compared with other surgical procedures; different stimuli such as rib spreading, costochondral dislocation, muscle division, use of diathermy, pleural trauma, pleural drains and subsequent neuroma formation, may play all a part in the development of post-thoracotomy pain.

The origin of pain after thoracic procedures is complex because there is a nociceptive excess carried by somatic and visceral fibers and a major neuropathic component.

According to the IASP (International Association of Pain), the post-thoracotomy pain syndrome is defined as the recurrence or persistence of pain more than two months after thoracotomy, without any recurrence of the disease. Neuropathic features as sensations of dysesthesia, allodynia or burning can be found in 35\% to $83 \%$ of cases (Maguire et al., 2006).

Dysaesthesia, which is frequently associated with chronic neuropathic pain, can occur in the form of heightened or diminished skin sensation: hypoesthesia (diminished sensation), hypoalgesia (diminished sensation from a painful stimulus), allodynia (pain from a stimulus that is not normally painful) and hyperalgesia (increasing sensation from a painful stimulus). Therefore, dysaesthesia in the early postoperative period may predict chronic pain.

Intercostal nerve damage may cause neuropathic pain through peripheral and central mechanisms. Neuropathic pain is characterized by an area of abnormal pain sensation co-existing with another area of sensory deficit. Often this is accompanied by a hyperpathic state including allodynia and hyperalgesia. Paresthesia has been defined as numbness or disordered sensation causing chest wall discomfort which the patient can distinguish clearly from the wound pain.

Rogers et al., 2000, describes chronic post-thoracotomy pain as a continuous dysaesthetic burning and aching pain in the general area of the incision that persists at least 2 months after thoracotomy. It occurs in approximately $50 \%$ of patients after thoracotomy and is usually mild or moderate. However, in $5 \%$ of patients is severe and disabling. 
Gotoda et al., 2001, studied 85 patients for persistent post-thoracotomy pain; a year after surgery, 35 patients (41.17\%) suffer persistent pain; 24 patients reported paresthesiadysesthesia and 14 patients complained of hypoesthesia. Clinical time course and symptoms indicate that nerve impairment rather than simple nociceptive impact may be involved in its etiology.

\section{Intercostal nerve impairment assessment}

The mechanisms producing chronicity in post-thoracotomy acute pain are complex and usually invoke intercostal nerve damage with a central sensitization phenomenon.

Direct injury of the intercostal nerve during thoracic surgery is not needed for symptoms to appear; the use of ratcheted rib spreaders may induce intercostal neuropathy some distance from the surgical site.

Benedetti et al., 1997, assessed intercostal nerve impairment after posterolateral thoracotomy measuring the superficial abdominal reflexes using electrophysiological techniques. They found a close correlation between pain intensity after posterolateral thoracotomy, absence of abdominal reflexes and less effective opioid response; the higher pain intensity with the absence of reflexes may be due to a larger neuropathic component.

Quantitative and selective assessment of intercostal nerve-fiber damage can be tested with a neurometer; current perception threshold values with 2000, 250 and $5 \mathrm{~Hz}$ stimuli indicate functions of $A \beta, A \delta$ and $C$ fibers respectively. $A \beta$ fibers are large fibers responsible for touch

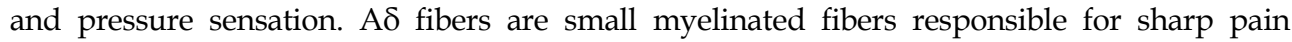
sensation. $\mathrm{C}$ fibers are umyelinated fibers responsible for sensing temperature and dull pain.

Intercostal nerve function was recently assessed (Miyazaki et al., 2011) after three different thoracic surgical procedures: video-assisted thoracic surgery (VATS), video-assisted minithoracotomy with metal retractor and conventional thoracotomy.

VATS group showed no changes in any current threshold values and no residual pain more than 12 weeks after surgery. The video-assisted minithoracotomy with metal retractors group and the conventional thoracotomy group showed significantly higher current perception threshold values at $2000 \mathrm{~Hz}, 1$ week after surgery with pain in approximately 70 $\%$ of patients 12 weeks after surgery.

The results of this study showed that the function of myelinated fibers (A $\beta$ and $A \delta$ ) was significantly impaired following surgery with metal rib retractors.

Rogers et al., 2002, registred nerve motor evoked potentials intraoperatively in order to identify intercostal nerve injury during thoracotomy; after the rib retractor was removed there was a total conduction block in the nerve immediately above the incision in every patient; if compression and ischaemia is applied to a nerve, neuropraxia will develop at a rate dependent upon severity of the insult.

Neuropraxia will resolve if the compression is removed in a short period of time and the nerve is allowed to recover. However, if the compression persists, then the neuropraxia becomes permanent as the nerve dies and loses its function. 
Another intra-operative intercostal nerve conduction study, revealed that nerve injury occurs either as a discrete block at the site of the retractor only, but conducts either side of this point or fails along the whole length of the nerve; These patterns of nerve injury are caused for two different mechanisms of injury: direct pressure on the nerve by the retractor causing a discrete point of trauma that is likely to develop relatively quick, and whilst traction on the nerve causing a much slower onset injury affecting the whole nerve, probably due to ischaemia of the persistently stretched tissues (Maguire et al., 2006).

\section{Thoracic surgical procedures}

Conventional thoracotomy requires a skin incision greater than $8 \mathrm{~cm}$, either if a posterolateral or an axillary approach was chosen. For the posterolateral incision, the latissimus, trapezius, and rhomboid muscles were divided; for the axillary incision only the serratus anterior muscle was split.

Muscle-sparing thoracotomy technique preserves the latissimus dorsi and serratus anterior muscles; after both muscles attachments are mobilized, latissimus dorsi muscle is retracted posteriorly and serrratus anterior muscle is retracted forward.

Minithoracotomy is a 7-8 $\mathrm{cm}$ chest wall incision for video-assisted procedures using several ports, two small metal retractors and a wound retractor.

Video-assisted thoracic surgery (VATS) procedures were performed by visualization through a television monitor; in most cases four or five ports were used and the main skin incision was just $4-5 \mathrm{~cm}$ long to remove the lung from the chest cavity with a wound retractor.

Benedetti et al., 1998, analyzed the degree of intercostal nerve impairment comparing posterolateral thoracotomy and muscle-sparing thoracotomy, correlating the nerve damage with long-lasting post-thoracotomy pain. The neurophysiologic recording performed 1 month after either posterolateral or muscle-sparing thoracotomy showed that patients who underwent a posterolateral thoracotomy had a higher degree of intercostal nerve impairment than the muscle sparing thoracotomy patients as revealed by disappearance of the abdominal reflexes, a larger reduction in amplitude of somatosensory-evoked potentials, and a larger increase of the sensory thresholds to electrical stimulation for both tactile perception and pain.

On the other hand, Khan et al., 2000, compared the early and/or late post-operative pain in posterior auscultation triangle thoracotomy incision (muscle-sparing) with full posterolateral thoracotomy (where latissimus dorsi muscle is always cut across its full width). They concluded that early and late post-thoracotomy pain and paraesthesia affecting the area of skin incision and anterior chest wall above and medial to the incision were similar in both incisions.

Similarly, Landreneau et al., 1996, compared the relative efficacies and rates of occurrence of acute or chronic morbidity after muscle-sparing thoracotomy (axillary or lateral) vs. standard lateral thoracotomy. There were no differences between thoracotomy approaches in any of the other primary acute postoperative variables analized (chest tube duration, length of hospital stay, postoperative narcotic requirements, and postoperative mortality). 
The frequencies of chronic pain and shoulder dysfunction assessed 1 year after operation were also similar between thoracotomy groups.

Division of serratus anterior and the latissimus dorsi muscles during posterolateral thoracotomy is thought to be related with major postoperative acute and chronic pain.

In muscle-sparing thoracotomy, usually two rib retractors are used instead just one: a small Finochietto rib retractor is positioned within the interspace to widen the intercostal opening; then, a second Finochietto retractor is positioned in a right-angled overlapping fashion with respect to the first retractor to displace the serratus anterior and the latissimus dorsi muscles posteriorly and the pectoralis major muscle anteriorly. During muscle-sparing incisions is necessary to spread the ribs wider apart than in a posterolateral thoracotomy in order to compensate for diminished field of view; in addiction, the use of two rib retractors to displace muscles cause injury to the nerves that would affect muscle function. The most obvious example of this would be injury to the long thoracic nerve, with resulting winged scapula.

\subsection{Intercostal nerve protecting surgical techniques}

The nerve damage is not significantly associated with most factors except for the technique of closure of the intercostal space: interrupted pericostal sutures are associated with $78 \%$ of the low nerve damage and $40 \%$ of the high nerve damage.

There are a few prospective studies regarding intercostal nerve protection during thoracotomy closure. Cerfolio et al., 2003, operated on 140 patients who underwent chest closure with pericostal sutures (placed on top of the fifth and seventh ribs) and compared to another 140 patients who underwent chest closure with intracostal sutures (placed on top of the fifth rib and through the small holes drilled in the bed of the sixth rib). They concluded that intracostal sutures were less painful than pericostal sutures, as evaluated at 2 weeks, 1 month, 2 months and 3 month after thoracotomy.

More recently, Bayram et al., 2011, compared two groups of patients who underwent posterior muscle-sparing minithoracotomy in the fifth interspace; in the patients of the group A, two holes were drilled into the sixth rib and sutures were passed through these holes and were circled from the upper edge of the fifth rib, thereby compressing the intercostal nerve underneath the fifth rib. In the group $B$, the intercostal muscle underneath the fifth rib was partially dissected along with the intercostal nerve, corresponding to the holes on the sixth rib, preventing fifth intercostal nerve compression. Patients of the group B had less post-operative pain as showed lower visual analog scores (VAS) at rest and during coughing.

The conception of a single intercostal nerve running the length of the space is incorrect. Before reaching the angle of the rib, the trunk of the intercostal nerve gives off a branch to the external intercostal muscle and then divides into three main branches:

An upper branch (anterior cutaneous) which occupies the subcostal groove and is the principal or main nerve.

A lower branch which runs for a varying distance along the upper border of the rib below (collateral nerve). 
An intermediate, the lateral cutaneous branch, which remains in the deep plane with the other branches until it reaches the level of its exits from the space, where it pierces the internal and external intercostal muscles obliquely ( Davies et al, 1932).

In a recent report (McAllister et al, 2011), cadaveric dissections of the $11^{\text {th }}$ intercostal space were performed to characterize intercostal nerve, artery and vein in relationship to the $11^{\text {th }}$ and $12^{\text {th }}$ ribs, in order to access the upper pole of the kidney and realize percutaneous nephrolitostomy. Access placements lateral to the paraspinous muscles and in the lower half of the $11^{\text {th }}$ intercostal space may decrease damage to the intercostal artery and nerve. So far, there are not similar studies in chest wall anatomy to reduce the damage of the intercostal nerves in VATS.

\subsection{Video-Assisted Thoracic Surgery}

Video-Assisted Thoracic Surgery (VATS) strongly reduces patient postoperative pain, hospital stay and analgesic requirements when compared to open surgery (Hazelrigg et al., 2000); however, over $50 \%$ of patients treated by VATS for spontaneous pneumothorax, complain of post-operative chest wall paresthesia related to the portal sites (Sihoe et al., 2004).

In order to improve the results of VATS, smaller instruments and scopes had been used.

Needlescopic instruments $(2 \mathrm{~mm})$ have been applied in treating primary spontaneous pneumothorax resulted in better cosmesis and less postoperative pain (Chen et al., 2003).

However, the incidence and nature of paresthesia remains similar even if the level of surgical trauma is further reduced by performing needlescopic VATS. After a needlescopic VATS sympathectomy (T2-T4) for palmar hyperhidrosis study, Sihoe et al., 2005, founded that $50 \%$ of patients complained of some type of paresthesic discomfort in the chest: bloating $(41.2 \%)$, pins and needles $(35.5 \%)$ or numbness $(23.5 \%)$.

Moreover, pre-emptive wound infiltration with local anesthetic ( $0.5 \%$ bupivacaine) reduced post-operative wound pain but not reduced chest wall paresthesia in patients who underwent needlescopic VATS sympathectomy for palmar hyperhidrosis (Sihoe et al., 2007).

It may be hypothesized that perhaps the local anesthesia was effective in blocking the sensitization to pain by sharp wound incision, but was less effective in preventing paresthesia which results from blunt trauma and compression to the intercostal nerves.

Although VATS is a minimal invasive surgery procedure, it not eliminates intercostal nerve injury since the scopes are heavily manipulated during procedure, which may cause the nerve to be crushed against the adjacent rib (figure 1).

Nowdays trend in VATS is to use fewer working ports to reduce even more postoperative pain, chest wall paresthesia and hospital stay.

One study compared one and two ports techniques for VATS thoracic sympathectomies; one-port group showed advantages in terms of hospital stay, rate of post-operative pneumothorax and the need for chest drain insertion (Murphy et al., 2006). 


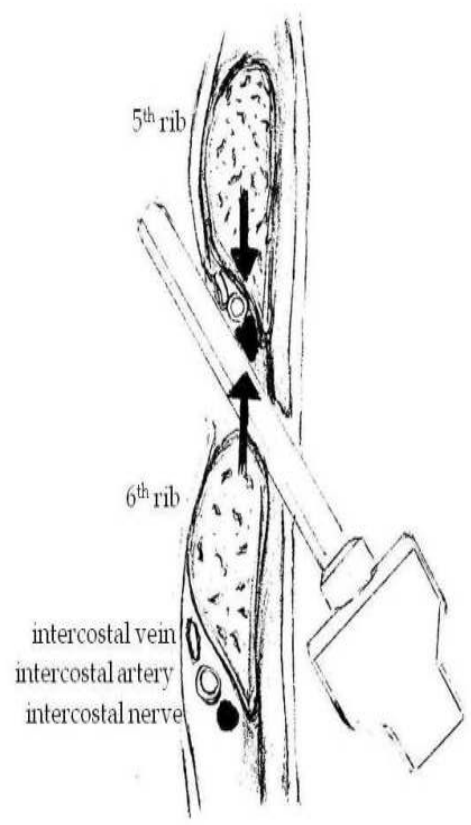

Fig. 1. Intercostal nerve compressed (black arrows) between a rigid port and the $5^{\text {th }}$ rib.

In 1998 was described for the first time the technique of single incision thoracic surgery for pneumothorax in six patients (Yamamoto et al., 1998). The authors were able to introduce a bronchoscope, a grasper and a stapler through a $2 \mathrm{~cm}$ long incision in the fifth intercostal space in the midaxillary line.

In other report, single incision VATS technique for spontaneous pneumothorax was used in 16 patients and compared retrospectively to 19 patients who underwent the standard three ports VATS technique; single incision VATS group showed less postoperative pain and lower incidence of residual paresthesias (Jutley et al., 2005).

A prospective no randomized trial, compared 28 patients operated on for spontaneous pneumothorax performing single incision thoracic technique (without protecting sleeves) with23 patients operated on with the standard three port VATS technique; the authors reported no increase of surgical costs, shorter hospital stay and decreased rate of chest wall paraesthesias (35\%), in the single incision group (Salati et al., 2008).

The authors (Berlanga \& Gigirey, 2011), reported an original technique of uniportal VATS for spontaneous pneumothorax using a single flexible laparoscopic in thirteen patients (Figure 2); three patients (23\%) presented mild chest wall paresthesia (numbness); two of them were transient paresthesias and the other one was successfully treated whit a eightweek course of Gabapentin ( $900 \mathrm{mg} /$ day in 3 doses).

The use of this single flexible port (SILS port ${ }^{\mathrm{TM}}$ ) in VATS procedures protects the intercostal nerves from compression due torquing of the camera or instruments and therefore reduces postoperative pain and rate of residual chest wall paresthesias. 


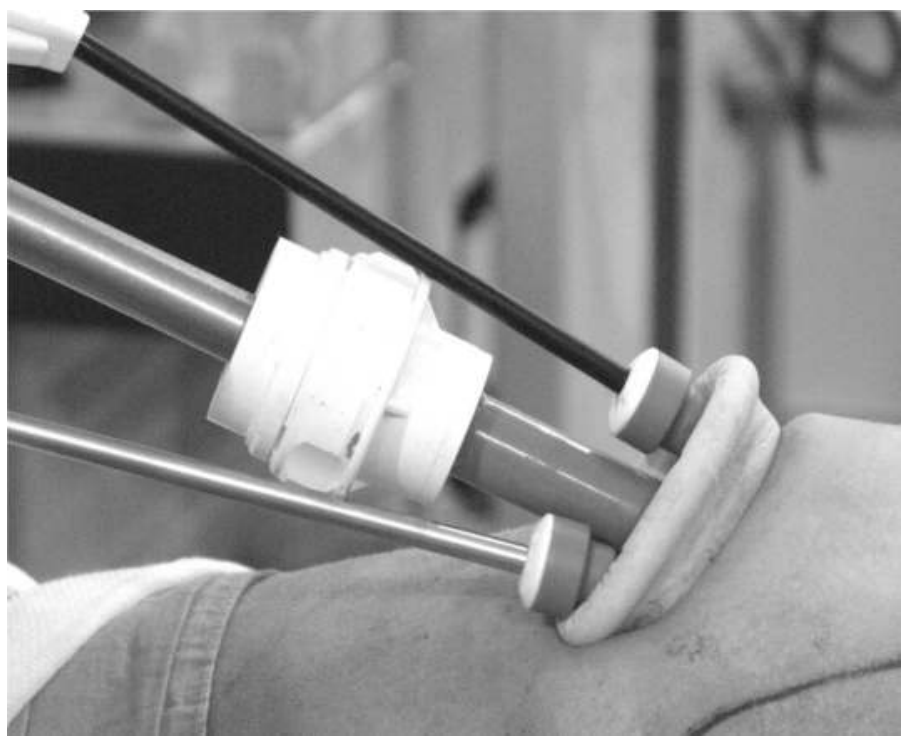

Fig. 2. Thoracoscope, stapler and endograsper introduced through the SILSTM port, lined up along the intercostal space.

Trauma to the intercostal nerves should be minimized by using $5 \mathrm{~mm}$ ports for thoracoscope and instruments whenever possible. The long-standing presence of the $10 \mathrm{~mm}$ thoracoscope torquing in a small intercostal space could well be responsible for the chronic pain syndrome.

Large port sleeves should be avoided with the only exception to the $12 \mathrm{~mm}$ port for the linear stapler; however the stapler does not remain in the intercostal space for any prolonged time.

\section{Pre-operative prediction of postoperative chronic pain}

Pre-operative pain is one of the best predictors of severe pain in the early post-operative period; a possible explanation for that is that chronic noxious afferent input has produced neuroplastic changes in the spinal cord (sensitization by upregulation of receptor subsystems) that become manifest as relatively hyperpathic state in the post-operative period. One clinical trial has demonstrated that the severe post-operative pain early after awakening from general anesthesia can be predicted at the pre-operative visit with a scoring rule, using the pain domain of the quality of life questionnaire Short form 36 (SF-36) and the Amsterdam Pre-operative Anxiety and information scale (APAIS), (Kalkman et al., 2003).

The transition of acute to chronic post-surgical pain is a complex and poorly understood process, involving biological, psychological and social-environmental factors. Several psychosocial predictors of chronic post-surgical pain have been identified, including increased pre-operative state anxiety, an introverted personality, social support, fear of surgery and "psychic vulnerability", a construct similar to neuroticism (Katz et al., 2009). 


\section{Pre-emptive analgesia}

Maybe the major justification for using pre-emptive anesthesia in thoracic surgery, is the clinical evidence that the decrease in acute post-thoracotomy pain may result in decreased risk of chronic post-thoracotomy pain syndrome.

The factors that affect the transition from acute to chronic pain, were studied in thirty patients who had undergone lateral thoracotomy. Fifty-two percent of these patients reported long-term pain. Early post-operative pain was the only factor that significantly predicted long-term pain. Pain intensity $24 \mathrm{~h}$ after surgery, at rest, and after movement, was significantly greater among patients who developed long-term pain compared with painfree patients (Katz et al., 1996).

Thoracic surgery patients treated with multimodal pre-emptive analgesia with morphine, indomethacin and intercostal nerve blockage with $0.5 \%$ bupivacaine, have shown no differences when comparing to control group in regard to postoperative pain VAS scores, $\mathrm{PaCO} 2$ values or postoperative spirometry (Kavanagh et al.,1994).

The pre-emptive effects of administering a 72-h epidural infusion of mepivacaine, beginning before surgery were compared to a postoperative epidural mepivacaine infusion in 70 patients who underwent thoracotomy. Follow-up at 3 and 6 months showed a significant reduction in the incidence of chronic post-thoracotomy pain in the group of patients that received the epidural before surgery (Obata et al.,1999).

Similarly, other authors have found satisfying results with pre-operatively initiated thoracic epidural analgesia in controlling post-thoracotomy pain in the acute and long-term period; they founded decreased incidence and intensity of chronic pain when compared to postoperative epidural or IV analgesia (Sentürk et al., 2002).

Conversely, in another prospective study designed to measure the pre-emptive effect of thoracic epidural analgesia, there was no difference in chronic pain incidence when compared axillary muscle-sparing thoracotomy vs. posterolateral thoracotomy (Ochroch et al., 2005).

Pre-emptive analgesia was intended to prevent the establishment of central sensitization caused by incisional and inflammatory injuries.

The results have not shown a major impact on postoperative pain after thoracic surgery, especially in preventing the development of chronic pain.

A possible explanation for the failure of pre-emptive epidural analgesia in prevent chronic post-thoracotomy pain is that the afferent blockage is not complete, given the variety of incoming stimuli that last for at least several days; in addition, is necessary a complete "humoral blockage" of circulating pro-inflammatory cytokines which lead to central COX-2 induction in the CNS (IL-1 $\beta$-mediated induction of COX-2), contributing to inflammatory pain hypersensitivity (Gerner et al., 2008).

On the other hand, in neuropathic animal pain models using rib retractors, nearly all myelinated fibers are damaged during the course of allodynia and a extensive Wallerian degeneration was observed 14 days post-surgery; if $0.5 \%$ bupivacaine is given systemically before surgery, mechanical allodynia is prevented (Shin et al., 2008).

This antiallodynic effect of bupivacaine, could be explained by three mechanisms: 
First, systemic anti-inflammatory action: after a peripheral nerve injury, the site of damage is typified by the activation of resident immune cells and recruitment and proliferation of nonneuronal elements like neutrophils; a number of soluble mediators can be released (IL-1 $\beta$ ) which initiate and maintain sensory abnormalities after injury. Similar to high-dose steroids, which have been proven to contribute to analgesia, local anesthetics including bupivacaine, have been shown to cause anti-inflammatory effects, preventing the release of cytokines.

Secondly, bupivacaine significantly inhibit N-methyl-D-aspartate (NMDA) receptors channel activation, which play an important role in secondary hyperalgesia and chronic pain syndromes.

Finally, subanesthetic doses of local anesthetic drugs, block sodium channel suppressing ectopic electrogenesis and may account for analgesic and antihyperalgesic effects of these drugs.

\section{Antiinflamatory drugs}

Local tissue damage results in inflammation and propagation of stimuli to the central nervous system. These stimuli are modulated by excitatory ( $\mathrm{N}$-methyl-D-aspartate) and inhibitory (opiate) pathways.

Elective surgery provokes an increase in the circulating cytokine levels, especially with regard to interleukin IL-6; the magnitude of the elevation levels is related directly to the degree of tissue injury.

Nagahiro et al. 2001, showed that post-operative pain measurements in VATS patients were significantly less than in posterolateral thoracotomy patients; also the serum interleukin-6 (IL-6) levels in VATS group patients were significantly decreased when compared with IL-6 serum levels in posterolateral thoracotomy group patients. When correlation between pain and cytokines serum levels was studied, a significant correlation was observed with IL-10 in all patients.

Analgesia with anti-inflammatory drugs may contribute to attenuate the postoperative inflammatory response and to prevent postoperative pain in patients undergoing thoracotomy. (NSAIDs) work by inhibiting the cyclooxygenase enzyme responsible for the release of mediators of inflammation.

Patients undergoing thoracotomy showed reduced postoperative pain, reduced analgesic consumption and decreased serum levels of acute phase reactants (IL-6, CPR), when flurbiprofen was added to the systemic analgesic therapy (Esme et al., 2011).

\section{Neuropathic pain treatment}

Chest wall paresthesia may represent a form of neuropathy following thoracic surgery that requires specific treatment by nonconventional analgesics or opiates drugs.

The prevalence of post-thoracotomy pain syndrome (PTPS) after 12-36 months of follow-up is persistently high; over $40 \%$ of patients still use conventional analgesics, but only $2 \%$ use neuropathic medication (Wildgaarg et al., 2010). 


\subsection{Gabapentin}

Gabapentin is an anticonvulsant drug that has antinoceptive and antihyperalgesic properties and is effective in treating chronic neuropathic pain by acting on an specific receptor (alpha 2 delta subunit of presynaptic type $\mathrm{N}$ voltage-dependent calcium channels), which are overexpressed in the dorsal horn of the spinal cord and spinal ganglia in cases of neurological injury (Laird et al., 2000).

There is a wide variability in gabapentin regimes depends on: pre-operative, peri-operative or post-operative long-term treatment, type of surgery, type of post-operative rescue analgesic and reported outcomes.

Differences in gabapentin doses as well as frequency of administration will undoubtedly introduce disparity in the pain outcomes.

A single pre-operative dose of gabapentin, $1200 \mathrm{mg}$ or less, effectively reduced pain intensity and opioid consumption for the first $24 \mathrm{~h}$ after surgery (Ho et al., 2006).

Turan et al., 2006, used a peri-operative regimen of gabapentin taking $1200 \mathrm{mg}$ preoperatively, followed by $1200 \mathrm{mg}$ on the morning of the first and second post-operative day.

Others (Fassoulaki et al., 2002) gave their patients $400 \mathrm{mg}$ of gabapentin the night before breast cancer surgery and then $400 \mathrm{mg}$ three times a day for 10 days.

Gabapentin has shown its effectiveness in the treatment of chronic pain after thoracic surgery decreasing, paresthesia around the wound in $75 \%$ of cases; $40 \%$ of the patients reported at least one minor side effect during treatment (somnolence or dizziness), but only in $6.7 \%$ of the patients, gabapentin had to be discontinued because of intolerance of side effects (Sihoe et al., 2006).

Effectiveness of gabapentin was also studied in the treatment of chronic post-throracotomy pain and compared with NSAIDs. Forty patients with posterolateral or lateral thoracotomy were prospectively studied to compare safety and efficacy of gabapentin to naproxen sodium.

Post-operative pain was evaluated by Virtual Analogue Scale (VAS) and the Leeds Assessment of Neuropathic Symptoms and signs (LANSS). At the latest follow up (60th day), the percentage of patients with VAS $<5$ was $85 \%$ in the gabapentin group and $15 \%$ in the naproxen group; similarly, the percentage of patients with LANSS score $<12$ was $85 \%$ in the gabapentin group and $0 \%$ in the naproxen group (Solak et al., 2007).

Pregabalin is another drug related to Gabapentin, indicated for neuropathic diabetic or postherpetic pain, but is not been well-studied in thoracic surgery patients.

\subsection{Capsaicin}

Topical capsaicin has been used as treatment for certain neuropathic pain states.

Its mechanism of action appears to be based on selective stimulation of the neurons of amyelinic fibers $C$, causing the release of substance $P$, which would disturb pain transmission to central system causing a desensitization phenomenon.

Peripheral neuropathic hypersensitivity is mediated by diverse mechanisms including altered expression of the capsaicin receptor TRPV1 or other key ion channels in affected or 
intact adjacent peripheral nociceptive nerve fibers, aberrant re-innervation and collateral sprouting, all of which are defunctionalized by topical capsaicin.

However, there are two major limitations to its use. First, modest efficacy of lowconcentration capsaicin formulations that are commercially available so far ( $1 \%$ or less), which require repeated daily self-administration. Second, compliance is poor because of intense initial burning effects.

Initial experiences with Capsaicin treatment at high doses $(5-10 \%)$ require regional anesthesia to tolerate side effects (Robbins et al., 1998).

High dose (8\%) concentration of capsaicin patch was recently approved in the EU and USA, a single 60-min application in patients with neuropathic pain produced effective pain relief for up to 12 weeks. Advantages of the high-concentration capsaicin patch include longer duration of effect, patient compliance and low risk for systemic effects or drug-drug interactions (Anad et al., 2011).

\section{Myofascial associated pain}

Post-operative pain in thoracic surgery is mainly nociceptive; however prolonged central sensitization evidenced as hyperalgesia does occur after surgical trauma and intercostal nerve damage; in addition, nonneuropathic pain can also occur following thoracic surgery.

Hamada et al. 2000, studied several patients with post-operative chronic pain (PTPS) in which myofascial pain was thought to be a causative component of post-thoracotomy pain syndrome. A trigger point in a taut muscular band within the scapular region was founded in $67 \%$ of these patients and was effectively treated with injections of $0.5 \%$ bupivacaine. The authors recommended that all PTPS patients should be examined in detail to determinate whether there is a trigger point in the scapula region.

\section{Surgical treatment for chronic thoracic pain}

Patients with chronic post-operative intercostal neuralgia that not response to medical treatment are candidates to surgical neurectomy. A recent study showed a successfully treatment in 5 patients with neurectomy proximal to the intercostal neurinoma of one or more intercostal nerves and implantation of the cut nerve into the latissimus dorsi muscle (Williams et al., 2008).

The site of resection along the course of the intercostal nerves is choosed depending upon the location of the patient's symptoms and the known anatomy of these nerves; if the patient has a pain in a dermatomal pattern but no motor weakness, it may be possible spare the motor portion of the intercostal nerve by resecting only the perforanting lateral cutaneous branch. If the motor function is nonfunctional or is expendable, then the entire intercostal nerve may be resected proximal to the lesion. If the pain is located only anteriorly, then only the anterior cutaneous branch maybe injured.

For patient who fails to improve after resection of intercostal nerves, there is still the possibility of doing a dorsal gangliectomy. 


\section{Immunology}

Hyperalgesia is commonly found in inflammatory pain conditions where damaged tissue is infiltrated with immune system cells, releasing a variety of soluble mediators that act on peripheral neurons. Allodynia may occur when nerves themselves are damaged (neuropathic pain) which occurs in situations such as diabetic neuropathy, HIV-associated neuropathy, or after surgical trauma.

Many inflammatory mediators (IL-1 and PGE2) act direct on sensory neurons and though cascades of second messengers and kinases, altering the sensitivity of both primary transducing receptors and sodium channels required for action potential transmission.

Pro-inflammatory cytokines can also directly activate and modify gene expression in sensory neurones, and there are several sources of these molecules in close proximity to peripheral nerves. Schwann cells, which have often been thought of having only a passive support role for peripheral nerves, are able to secrete pro-inflammatory cytokines, including via a purinergic P2X7-mediated mechanism (Samad et al., 2001).

Administration of growth factors, such as glial cell line-derived neurotrophic factor (GDNF), could prevent injury-induced transcriptional changes in sensory neurons. Other treatment modalities include the prevention of microglial activation with drugs like minocycline or neuroprotective strategies designed to prevent apoptosis in the dorsal root ganglion or dorsal horn.

Some experimental trials have shown the effects of receptor potential vanilloid 1 (TRPV1) antagonist in regard to improve post-operative analgesia or to reduce the mechanical allodynia.

The analgesic effects of a recently developed transient receptor potential vanilloid 1 (TRPV1) antagonist (AMG0347) were studied in an experimental model of incisional pain (Wu C, et al., 2008). The authors founded that AMG0347 decreased capsaicin-induced heat and mechanical hyperalgesia and blocked central and peripheral TRPV1 receptors. Resiniferatoxin (RTX) is very potent vanilloid receptor against molecularly analogous to capsaicin that causes a slow sustained activation of transient receptor potential vanilloid1 (TRPV-1) receptor.

However, RTX has shown controversial results regarding its use in the treatment of experimental models of chronic pain. Others authors reported that RTX intercostal injections causes a transient hyperalgesic response in injured animals and is ineffective in reducing the mechanical allodynia after thoracotomy (Shin et al., 2010).

\section{Genetics}

Pain perception is one of the most complicated measurable traits because there is an aggregate of several phenotypes associated with peripheral and central nervous system dynamics, stress responsiveness and inflammatory state.

The manner in which an individual experiences pain and the magnitude of the response to a given pain stimulus may reflect a genetic "set point" in pain sensitivity, irrespective of the degree of tissue damage or inflammation (Diatchenko et al., 2007). 
Genetic association studies of pain pathways have complemented the traditional neuroscience approaches of electrophysiology and pharmacology and may point to the novel molecules that mediate neuropathic pain, facilitating its understanding and management.

Recent candidate gene studies have identified and replicated the first associations between several common polymorphisms and pain severity in humans.

Certain allelic variants of the MHC could influence susceptibility to develop and maintain neuropathic pain-like behavior following peripheral nerve injury (Dominguez et al., 2008).

Human genome-wide association studies of pain phenotypes might identify novel analgesic targets, help to prioritize research among current targets, and increase the likelihood of success for analgesics candidates emerging from animal studies.

A range of genetic variations that alter the effectiveness of analgesic drugs, have been identified. In particular, polymorphisms of the cytochrome P450 enzymes (CYP), which play a key role in the metabolism of many drugs, can affect the efficacy of opiates and NSAIDs.

There are some critical regulators of altered pain states, including genes nor normally expressed in the nervous system, but present in cells of the immune system that also are activates in situations of tissue damage. For example, P2RX7, an ATP receptor absent from neurons but present on macrophages and microglia, which is essential for altered inflammatory or neuropathic pain (Foulkes et al., 2008).

In another experimental model of incisional pain, was demonstrated that the heat allodynia and spontaneous firing of impulses in C-fibers innervating the skin adjacent to the incision, depend on Vanilloid 1 transient receptor potential (Trpv1) receptors, and the allodynia and firing of C-fibers were much reduced in Trpv1 gene knockout mice (Banik et al., 2009).

\section{Conclusion}

The sensation of pain in response to a normal non-painful stimulus (allodynia) or to an exaggerated response to slightly painful stimulus (hyperalgesia), especially when accompanied by numbness, is considered diagnostic for nerve injury.

Although no one thoracic surgical technique has been proved to decrease the incidence of chronic pain, intercostal nerve damage due to rib retraction seems involved in the development of neuralgia.

Video-assisted thoracic surgery reduces postoperative pain, analgesic requirements, hospital stay and the rate of chest paresthesias when compares to open thoracic surgery; residual chest wall paresthesias rate reduces more with the use of flexible ports and uniportal techniques than with the use of needlescopic instruments.

Neuropathic postoperative pain should be identified and treated with anticonvulsant drugs (gabapentin, pregabalin); topical treatment with high dose capsaicin patchs is a value complement.

Future clinical researches in genetics and immunology will help to identify susceptible phenotypes, polymorphisms and allelic variants associated to develop neuropathic pain, as well as, to identify novel analgesic targets to improve postoperative analgesia or to reduce mechanical allodynia. 


\section{References}

Anad P \& Bley K. Topical capsaicin for pain manegment: therapeutic potential and mechanism of action of the new high-concentration capsaicin $8 \%$ patch. Br J Anaesth 2011 Aug 17. (Epub ahead of print).

Bayram AS, Ozcan M, Kaya FN, \& Gebitekin C. Rib approximation without intercostal nerve compression reduces post-thoracotomy pain: a prospective randomized study. Eur J Cardiothorac Surg 2001;39:570-574.

Benedetti F, Amanzio M, Casadio C, Filosso PL, Molinatti M, Oliaro A, Pischedda F, \& Maggi G. Postoperative pain and superficial abdominal reflexes after posterolateral thoracotomy. Ann Thorac Surg. 1997;64:207-10.

Benedetti F, Vighetti S, Ricco C, Amanzio M, Bergamasco L, Casadio C, Cianci R, Giobbe R, Oliaro A, Bergamasco B, \& Maggi G. Neurophysiologic assessment of nerve impairment in posterolateral and muscle-sparing thoracotomy. J Thorac Cardiovasc Surg.1998;115:841- 847.

Berlanga L, \& Gigirey O. Uniportal video-assisted thoracic surgery for primary spontaneous pneumothorax using a single-incision laparoscopic surgery port: a feasible and safe procedure. Surg Endoscopy 2011;25:2044-2047.

Cerfolio RJ, Price TN, Bryant AS, Bass CS, \& Bartolucci AA. Intracostal sutures decreases the pain of thoracotomy. Ann Thorac Surg 2003;776:407-412.

Davies F, Gladstone RJ, \& Stibbe EP. The anatomy of the intercostal nerves. J Anat 1932;66:323-33.

Diatchenko L, Nackley AG, Tchvileva IE, Shabalina SA, \& Maixner W. Genetic Architecture of human pain perception. Trends Genet 2007;23:605-607.

Domínguez CA, Lidman O, Hao JX, Diez M, Tuncel J, Olsson T, Wiesenfeld-Hallin Z, Piehl $\mathrm{F}, \& \mathrm{Xu}$ XJ. Genetic analysis of neuropathic pain-like behavior following peripheral nerve injury suggests a role of major histocompatibility complex in development of allodynia. Pain 2008;136:313-319.

Esme H, Kesli R, Apillogullari B, Duran FM, \& Yoldas B. Effects of Flurbiprofen on CRP, TNF-a, IL-6 and Postoperative Pain of Thoracotomy. Int J Med 2011;8:216-221.

Fassoulaki A, Patris k, Sarantopoulos C, \& Hogan Q. The analgesic effect of gabapentin and mexiletine after breast surgery for cancer. Anesth Analg 2002.;95:985-991.

Foulkes T, \& Wood, JN. (2008) Pain Genes. PLoS Genet 4: e1000086.

Gerner P. Post-thoracotomy Pain Management Problems. Anesthesiol Clin 2008;26:235-367.

Gotoda Y, Kambara N, Sakai T, Kishi Y, Kodama K, \& Koyama T. The morbidity, time course and predictive factors for persistent post-thoracotomy pain. Eur J Pain 2001:5:89-96.

Hamada H, Moriwaki K, Shiroyama K, Tanaka H, Kawamoto M, \& Yuge O. Myofascial pain in patients with postthoracotomy pain syndrome. Reg Anesth Pain Med 2000;25:302305.

Hazelrigg SR, Magee MJ, \& Boley TM. (2000). Video-Assisted Spontaneous pneumothorax. In: Minimal access cardiothoracic surgery. Yim APC, Hazerlrigg SR, Izatt MB, Landreneau RJ, Mack MJ, Naunheim KS, eds. pp. (73-79). Saunders, Philadelphia, PA.

Ho KY, Gan TJ, \& Habib AS. Gabapentin and postoperative pain - a Systematic review of randomized controlled trials. Pain 2006;126:91-101. 
Jutley RS, Khalil MW, \& Rocco G. Uniportal vs. standard three-port VATS technique for spontaneous pneumothorax: comparison of post-operative pain and residual paraesthesia. Eur J Cardiothorac Surg 2005;28:43-46.

Kalkman CJ, Visser K, Moen J, \& Bonsel DE. Preoperative prediction of severe pain. Pain 2003;105:415-423.

Katz J, Jackson M, \& Kavanagh BP, et al. Acute pain after thoracic surgery predicts longterm post-thoracotomy pain. Clin J Pain 1996;12:50-55.

Katz J, \& Seltzer Z. Transition from acute to chronic postsurgical pain: risk factors and protective factors. Expert Rev Neurother 2009;9:723-744.

Kavanagh BP, Katz J, Sandler AN, Nierenberg H, Roger S, Boylan JF, \& Laws AK. Multimodal analgesia before thoracic surgery does not reduce postoperative pain. Br J Anaesth 1994;73:184-189.

Khan IH, McManus KG, McCraith A, \& McGuigan JA. Muscle sparing thoracotomy: a biomechanical analysis confirms preservation of muscle strength but no improvement in wound discomfort. Eur J Cardiothorac Surg 2000;18:656-661.

Laird MA, \& Gidal BE. Use of gabapentin in the treatment of neuropathic pain. Ann Pharmacother. 2000;34:802-7.

Landreneau RJ, Pigula F, Luketich JD, Keenan RJ, Bartley S, Fetterman LS, Bowers CM, Weyant RJ, \& Ferson P. Acute and chronic morbidity differences between musclesparing and standard lateral thoracotomies. J Thorac Cardiovasc Surg 1996;112:13461351.

Maguire M, Ravenscroft A, Beggs D, \& Duffy J. A questionnaire study investigating the prevalence of the neuropathic component of chronic pain after thoracic surgery. Eur J Cardiothorac Surg. 2006a;29:800-805.

Maguire MF, Latter JA, Mahajan R, Beggs FD, \& Duffy JP. A study exploring the role of intercostals nerve damage in chronic pain after thoracic surgery. Eur J Cardiothorac Surg 2006b;29:873-879.

McAllister M, Lim K, Torrey R, Chenoweth J, Barker B, \& Baldwin D. Intercostal vessels and nerves are at risk for injury during supracostal percutaneous nephrolitostomy. $J$ Urol 2011;185:329- 334.

Miyazaki T, Sakai T, Tsuchiya T, Yamasaki N, Tagawa T, Mine M, Shibata Y, \& Nagayasu T. Assessment and follow-up of intercostals nerve damage after video-assisted throracic surgery. Eur J Thorac Surg 2011;39:1033-1039.

Murphy MO, Ghosh J, Khwaja N, Murray D, Halka AT, Carter A, Turner NJ, \& Walker MG. Upper dorsal endoscopic thoracic sympathectomy: a comparison of one-and two ablation techniques. Eur J Cardiothorac Surg 2006;30:223-227.

Nagahiro I, Andou A, Aoe M, Sano Y, Date H, \& Shimizu N. Pulmonary function, postoperative pain, and serum cytokine level after lobectomy: a comparison of VATS and conventional procedure. Ann Thorac Surg 2001;72:362-365.

Obata H, Saito S, \& Fujita N. Epidural block with mepivacaine before surgery reduces longterm post-thoracotomy pain. Can J Anaesth 1999; 46:1127-1132.

Ochroch EA, Gottschalk A, Augoustides JG, Aukburg SJ, Kaiser LR, \& Shrager JB. Pain and physical function are similar following, muscle-sparing vs. posterolateral thoracotomy. Chest 2005;128:2664-2670.

Robbins WR, Staats PS, Levine J, \& Fields H. Treatment of intractable pain with topical large-dose Capsaicin: Preliminary report. Anesth Analg 1998;86:579-83. 
Rogers ML, \& Duffy JP. Surgical aspects of chronic post-thoracotomy pain. Eur J Cardiothorac Surg. 2000;18:711-6.

Rogers ML, Hendersion L, Mahajan RP, \& Duffy JP. Preliminary findings in neurophysiological assessment of intercostal nerve injury during thoracotomy. Eur J Cardiothorac Surg 2002;21:298-301.

Salati M, Brunelli A, Xiumè F, Refai M, Sciarra V, Soccetti A, \& Sabbatini A. Uniportal video assisted thoracic surgery for primary spontaneous pneumothorax: clinical and economic analysis in comparison to the traditional approach. Interact Cardiovasc Thorac Surg 2008;7:63-66.

Samad TA, Moore KA, Sapirstein A, Billet S, Allchrone A, Poole S, Bonventre JV, \& Woolf CJ. Interleukin-1beta-mediated induction of Cox-2 in the CNS contributes to inflammatory pain hypersensitivity. Nature 2001;410:471-475.

Sentürk M, Ozcan PE, Talu GK, Kiyan E, Cami E, Ozyalcin S, Dilege S, \& Pembeci K. The effects of three different analgesia techniques on long-term posthoracotomy pain. Anesth Analg 2002;94:11-15.

Shin JW, Pancaro C, Wang CF, \& Gerner P. Low-dose systemic bupivacaine prevents the development of allodynia after thoracotomy in rats. Anesth Analg 2008;107:15871591.

Shin JW, Pancaro C, Wang CF, \& Gerner P. The effects of Resiniferatoxin in an experimental rat thoracotomy model. Anesth Analg 2010;110:228-232.

Sihoe AD, Au SS, Cheung ML, Chow IK, Chu KM, Law CY, Wan M, \& Yim AP. Incidence of chest wall paraesthesia after video assisted surgery for primary spontaneous pneumothorax. Eur J Cardiovasc Surg 2004;24:1054-1058.

Sihoe AD, Cheung C, Lai HK, Lee TW, Thung KH, \& Yim, A. Incidence of chest wall paresthesia after needlescopic video-assisted thoracic surgery for palmar hyperhidrosis. Eur J Cardiothorac Surg. 2005;27:313-319.

Sihoe AD, Lee TW, Wan IY, Thung KH, \& Yim AP. The use of gabapentin for post-operative and post-traumatic pain in thoracic surgery patients. Eur J Cardiothorac Surg 2006;29:795- 799 .

Sihoe AD, Manlulu AV, Lee TW, Wan IY, Thung KH, \& Yim AP. Pre-emptive local anesthesia for needlescopic video-assisted thoracic surgery: a randomized controlled trial. Eur J Cardiothorac Surg 2007;31:103-108.

Solak O. Merin M \& Esme H. Effectiveness of gabapentin in the treatment of chronic postthroracotomy pain. Eur J Cardiothoracic Surg 2007;32:9-12.

Wildgaard K, Ravn J, Nikolajsen L, \& Jakobsen E. Consequences of persistent pain after lung cancer surgery: a nationwide questionnaire study. Acta Anaesthesiol Scand 2010;55:60-68.

Wu C, Gavva NR, \& Brennan TJ. Effect of AMG0347, a transient potential type V1 receptor antagonist and morphine on pain behavior after plantar incision. Anesthesiology 2008;108:1100-1108.

Yamamoto H, Okada M, Takada M, Mastuoka H, Sakata K, \& Kawamura M. Thoracic Surgery Though a Single Skin Incision. Arch Surg. 1998;133:145-147. 


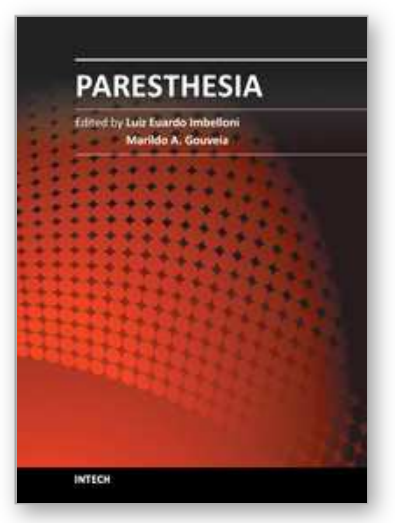

\author{
Paresthesia \\ Edited by Dr. Luiz Eduardo Imbelloni
}

ISBN 978-953-51-0085-0

Hard cover, 90 pages

Publisher InTech

Published online 29, February, 2012

Published in print edition February, 2012

Paresthesias are spontaneous or evoked abnormal sensations of tingling, burning, pricking, or numbness of a person's skin with no apparent long-term physical effect. Patients generally describe a lancinating or burning pain, often associated with allodynia and hyperalgesia. The manifestation of paresthesia can be transient or chronic. Transient paresthesia can be a symptom of hyperventilation syndrome or a panic attack, and chronic paresthesia can be a result of poor circulation, nerve irritation, neuropathy, or many other conditions and causes. This book is written by authors that are respected in their countries as well as worldwide. Each chapter is written so that everyone can understand, treat and improve the lives of each patient.

\title{
How to reference
}

In order to correctly reference this scholarly work, feel free to copy and paste the following:

Luis Berlanga González, Orlando Gigirey Castro and Sara de Cabanyes Candela (2012). Chest Wall Paraesthesia After Thoracic Surgery, Paresthesia, Dr. Luiz Eduardo Imbelloni (Ed.), ISBN: 978-953-51-0085-0, InTech, Available from: http://www.intechopen.com/books/paresthesia/chest-wall-paraesthesia-after-thoracicsurgery

\section{INTECH}

open science | open minds

\section{InTech Europe}

University Campus STeP Ri Slavka Krautzeka 83/A 51000 Rijeka, Croatia

Phone: +385 (51) 770447

Fax: +385 (51) 686166 www.intechopen.com

\section{InTech China}

Unit 405, Office Block, Hotel Equatorial Shanghai No.65, Yan An Road (West), Shanghai, 200040, China 中国上海市延安西路65号上海国际贵都大饭店办公楼 405 单元 Phone: +86-21-62489820

Fax: +86-21-62489821 
(C) 2012 The Author(s). Licensee IntechOpen. This is an open access article distributed under the terms of the Creative Commons Attribution 3.0 License, which permits unrestricted use, distribution, and reproduction in any medium, provided the original work is properly cited. 